\title{
The effect of hybridization of Culex pipiens complex mosquitoes on transmission of West Nile virus
}

\author{
Alexander T Ciota ${ }^{1}$, Pamela A Chin ${ }^{1}$ and Laura D Kramer ${ }^{1,2^{*}}$
}

\begin{abstract}
Background: Culex pipiens L. complex mosquitoes have a global distribution and are primary vectors of pathogens of public health significance. In the U.S., CX. pipiens bioformes, CX. pipiens form pipiens and CX. pipiens form molestus, as well as Cx. quinquefasciatus, are primary vectors of West Nile virus (WNV; Flaviviridae, Flavivirus). These mosquitoes reside in distinct but overlapping ecological niches and readily hybridize in areas where they coexist. Although species and population-specific differences in vector competence of Culex mosquitoes for WNV have been identified, the extent to which hybridization within this complex alters WNV transmission potential has not been well characterized.
\end{abstract}

Findings: WNV vector competence of laboratory colonies of $C x$. p. f. pipiens, $C x . p$. f. molestus, and $C X$. quinquefasciatus was assessed and compared to hybrid populations created from reciprocal mating of these lines. The results demonstrate that hybridization has a significant effect on WNV infection, dissemination, and, particularly, transmission in Culex pipiens L. complex mosquitoes. Specifically, enhanced transmission of WNV was measured in all hybrid populations relative to one or both parental stains.

Conclusion: These findings demonstrate that environmental or anthropogenic changes resulting in fluctuations in the distribution and extent of hybrid populations of Culex mosquitoes could have a significant impact on transmission patterns of WNV in nature.

\section{Findings}

\section{Introduction}

The Culex pipiens L. complex includes $C x$. pipiens and $C x$. quinquefasciatus in North America, South America, Africa, and Asia; as well as Cx. australicus and Cx. globocoxitus in Australia [1]. Mosquitoes in this complex are primary vectors of West Nile virus (WNV; Flaviviridae, Flavivirus) in the United States, i.e., $C x$ pipiens north of $36^{\circ}$ latitude and $C x$ quinquefasciatus, south [2,3], with hybrids of the two found in a zone stretching from approximately $30^{\circ} \mathrm{N}$ to $40^{\circ} \mathrm{N}$ latitude in N. America [4,5]. Each species possesses a unique genetic signature as well as distinct physiology $[6,7]$. $C x$ pipiens is comprised of two bioformes, $C x$ pipiens form pipiens and $C x$ pipiens form molestus. $C x . p$. f. molestus populations are present throughout the Americas where

\footnotetext{
* Correspondence: Idk02@health.state.ny.us

${ }^{1}$ The Arbovirus Laboratories, Wadsworth Center, New York State Department of Health, Slingerlands, NY 12159, USA

${ }^{2}$ School of Public Health, SUNY, Albany, NY 12201, USA
}

they are most often found in more subterranean areas, whereas $C x$. $p$. f. pipiens and $C x$. quinquefasciatus occupy aboveground habitats. Additional biological differences further distinguish $C x . p$. f. molestus, including autogeny, mating in enclosed spaces, and lack of diapause $[2,8]$. An excellent review of the $C x$. pipens complex has been published elsewhere [1]. Although many Northern European populations of $C x . p$. f. pipiens are pure, U.S. populations generally contain varying levels of $C x . p$. f. molestus signature, a characteristic which may increase propensity for $\mathrm{U}$. S. Cx. pipiens to feed on mammals and contribute to the increased number of human cases of WNV in the U.S. [9]. Vector competence for WNV also has been shown to vary among Culex species and populations [10,11], yet the extent to which hybridization within this complex alters WNV transmission has not been fully evaluated. Here, we sought to characterize variation in WNV transmission potential in laboratory colonies of $C x . p$. f. pipiens, $C x p$. f. molestus, and $C x$. quinquefasciatus, as well as hybrids
C Biomed Central

(C) 2013 Ciota et al.; licensee BioMed Central Ltd. This is an open access article distributed under the terms of the Creative Commons Attribution License (http://creativecommons.org/licenses/by/2.0), which permits unrestricted use, distribution, and reproduction in any medium, provided the original work is properly cited. 
resulting from mating of these parental lines. Our results demonstrate that the extent of hybridization among $C x$. pipiens complex mosquitoes may significantly alter patterns of WNV transmission in the U.S.

\section{Methods \\ Mosquitoes}

All colonized Culex mosquitoes were maintained in $30.5 \mathrm{~cm}^{3}$ cages in an environmental chamber at $27+/-$ $2^{\circ} \mathrm{C}$ with a relative humidity of $45-65 \%$ and a photoperiod of 16:8 (light:dark) hours prior to the collection of experimental egg rafts. $C x$. $p$. f. pipiens colony mosquitoes were originally collected in Pennsylvania in 2004 (courtesy of M. Hutchinson) and colonized at the Arbovirus laboratory. $C x$. quinquefasciatus colony mosquitoes were derived from a laboratory colony provided by $\mathrm{D}$. Fonseca (Rutgers Univ.) derived from egg rafts from Benzon Research Inc. (Carlisle, PA) originating from a highly colonized US population. $C x . p$. f. molestus were colonized in 2009 following collection from the basement of the state house in New Jersey (courtesy of D. Fonseca). Two-way crosses were completed with the 3 parental strains to produce hybrid progeny. Genetic signatures were confirmed using species-specific primers on a subset (10 individuals) of F0 and F1 mosquitoes $[12,13]$. Parental $C x . p$. f. pipiens were confirmed to be genetically distinct from $C x$. quinquefasciatus yet, as expected, did contain $C x . p$. f. molestus signature. $C x$. quinquefasciatus and $C x$. p. f. molestus individuals tested were genetically pure at the loci evaluated and the presence of mixed signatures were confirmed among all F1 hybrid populations used for experimental feedings.

\section{Experimental infections and vector competence}

WNV strain WNV02-1956 was originally isolated from an American crow in New York State in 2005 and passaged once on mammalian cells (Vero; ATCC CC1-81) and once on Aedes albopictus mosquito cells (C6/36, ATCC CRL-1660). After an additional passage of 72 hours on C6/36 cells, supernatants and cells from infected cultures were mixed 1:1 with defibrinated bovine blood (HemaResources, Inc, Aurora, OR) plus a 2.5\% final sucrose concentration. 7-day old female mosquitoes were deprived of sucrose for 12-16 hours and offered a porcine sausage casing filled with the bloodmeal mixture. Following 1 hour, mosquitoes were sedated with $\mathrm{CO}_{2}$ and fully engorged mosquitoes were transferred to $0.6 \mathrm{~L}$ cartons and maintained at $27^{\circ} \mathrm{C}$ for experimental testing. Infection, dissemination, and transmission rates were determined as previously described [14] on days 7 and 13/14 post-feeding. 25-50 mosquitoes/timepoint/ group/experiment were sedated and legs were removed and placed in $1 \mathrm{ml}$ mosquito diluent [MD; 20\% heatinactivated fetal bovine serum (FBS) in Dulbecco's phosphate-buffered saline (PBS) plus $50 \mu \mathrm{g} / \mathrm{ml}$ penicillin/streptomycin, $50 \mu \mathrm{g} / \mathrm{ml}$ gentamicin, and $2.5 \mu \mathrm{g} / \mathrm{ml}$ Fungizone]. Mosquitoes were allowed to expectorate for approximately 30 minutes into capillary tubes filled with FBS plus 50\% sucrose (1:1), at which time the mixture was ejected into $0.3 \mathrm{ml} \mathrm{MD}$. Mosquito bodies were then placed in individual tubes with MD. All samples were held at $-80^{\circ} \mathrm{C}$ until tested. Bodies, legs, and salivary secretions were processed and screened by duplicate plaque assay on Vero cells to test for infection, dissemination, and transmission, respectively. Data were analyzed using GraphPad prism 4.0 and rates were compared with Pearson's chi-squared tests.

\section{Results and discussion}

Vector competence experiments were completed three times and experimental data were combined following confirmation of both equivalent WNV bloodmeal titers and infection rates of genetically similar groups. Variation among dissemination and transmission rates was observed, yet similar trends among individual populations were evident. Mean bloodmeal titers were $9.2 \log _{10}$ $\mathrm{WNV} / \mathrm{ml}$. Although this dose mimics peak viremia of some bird species, particularly Passeriformes [15], it is on the high end of what a mosquito would encounter in nature and therefore explains the relatively high infection and dissemination rates measured in all groups (Table 1). Despite this, some differences in infection and dissemination were identified. Among parental populations, $C x$. quinquefasciatus were the most susceptible, with $100 \%$ infection at both timepoints, significantly higher than both $C x . p$. f. molestus and $C x . p$. f. pipiens (chi-squared, $\mathrm{p}<0.05$; Table 1 ). Although some small differences were identified on day 7 , dissemination rates among parental populations were equivalent by day 13/ 14. As with infection, transmission rates were highest among $C x$. quinquefasciatus, and this difference was significant relative to both other colonies by day $13 / 14$ (chi-squared, $\mathrm{p}<0.05$; Table 1 ). Cx. quinquefasciatus have been shown previously to be highly competent WNV vectors [16,17], yet the increased competence relative to other species demonstrated here is likely to be population-dependent [18].

Assay of hybrid mosquitoes demonstrated that the presence of $C x$. quinquefasciatus signature increased susceptibility to infection, with $100 \%$ infection rates measured in all hybrid groups derived from $C x$. quinquefasciatus parentals (Table 1). Additional effects of hybridization on infection were measured with crosses of $C x . p$. f. molestus and $C x . p$. $\mathrm{f}$. pipiens, with rates generally mimicking the more susceptibility parental strain; yet the most significant effects of hybridization were measured with transmission rates. Specifically, the percent of infected hybrid populations transmitting by day $13 / 14$ was either equivalent to the parental 
Table 1 Vector competence of Culex mosquitoes for WNV02 following feeding on infectious bloodmeals

\begin{tabular}{|c|c|c|c|c|}
\hline Population (female $x$ male) & Day & $\%$ Infected $^{1}$ & $\%$ Infected disseminating & $\%$ Infected transmitting \\
\hline \multirow[t]{2}{*}{$C x . p$ f pipiens $(\mathrm{CxP})$} & 7 & $89.3^{\mathbf{M} \uparrow \mathbf{Q} \downarrow}$ & $89.6^{\mathbf{Q} \uparrow}$ & $3.0^{\mathrm{M}, \mathbf{Q} \downarrow}$ \\
\hline & $13 / 14$ & $83.6^{\mathrm{Q} \downarrow}$ & 98.4 & $34.4^{Q \downarrow \downarrow}$ \\
\hline \multirow[t]{2}{*}{ Cx. quinquefasciatus (CxQ) } & 7 & $100^{\mathrm{M}, \mathrm{P} \uparrow}$ & $69.3^{P \downarrow}$ & $24.0^{\mathbf{P} \uparrow}$ \\
\hline & $13 / 14$ & $100^{\mathrm{M}, \mathrm{P} \uparrow}$ & 95.8 & $63.4^{\mathrm{M}, \mathrm{P} \uparrow}$ \\
\hline \multirow[t]{2}{*}{$C x . p$ f molestus (CxM) } & 7 & $69.6^{\mathrm{P}, \mathrm{Q} \downarrow}$ & 77.1 & $16.7^{\mathbf{P} \uparrow}$ \\
\hline & $13 / 14$ & 93.1 & 90.0 & $37.5^{Q} \downarrow$ \\
\hline \multirow[t]{2}{*}{$\mathrm{CxM} \times \mathrm{CxP}$} & 7 & $89.3^{\mathbf{M} \uparrow}$ & $71.6^{\mathbf{P} \downarrow}$ & 13.4 \\
\hline & $13 / 14$ & $76.0^{\mathrm{M}, \mathrm{P} \downarrow}$ & 93.0 & $57.9^{\mathrm{M}, \mathrm{P} \uparrow}$ \\
\hline \multirow[t]{2}{*}{$\mathrm{CxP} \times \mathrm{CxM}$} & 7 & $93.3^{\mathbf{M} \uparrow}$ & $70.0^{\mathbf{P} \downarrow}$ & 7.1 \\
\hline & $13 / 14$ & $94.6^{\mathbf{P} \uparrow}$ & 97.1 & $61.4^{\mathrm{M}, \mathrm{P} \uparrow}$ \\
\hline \multirow[t]{2}{*}{$C x M x C x Q$} & 7 & $100^{\mathbf{M} \uparrow}$ & 64.0 & $8.0^{\mathrm{Q} \downarrow}$ \\
\hline & $13 / 14$ & 100 & 94.7 & $62.7^{M \uparrow}$ \\
\hline \multirow[t]{2}{*}{$\mathrm{CxQ} \times \mathrm{CxM}$} & 7 & $100^{\mathbf{M} \uparrow}$ & 58.7 & $5.3^{Q} \downarrow$ \\
\hline & $13 / 14$ & 100 & 93.9 & $66.1^{\mathrm{M} \uparrow}$ \\
\hline \multirow[t]{2}{*}{$C x P \times C x Q$} & 7 & $100^{\mathbf{P} \uparrow}$ & $69.3^{P \downarrow}$ & $2.7^{\mathrm{Q} \downarrow}$ \\
\hline & $13 / 14$ & $100^{P \uparrow}$ & 97.3 & $62.7^{P \uparrow}$ \\
\hline \multirow[t]{2}{*}{$C \times Q \times C x P$} & 7 & $100^{\mathbf{P} \uparrow}$ & $86.7^{\mathbf{Q} \uparrow}$ & $18.7^{\mathbf{P} \uparrow}$ \\
\hline & $13 / 14$ & $100^{\mathbf{P} \uparrow}$ & 100 & $80.3^{\mathbf{P}, \mathbf{Q} \uparrow}$ \\
\hline
\end{tabular}

${ }^{1} 65-75$ total mosquitoes tested/population/timepoint.

M,Q,P denotes significant differences in populations (chi-squared, $\mathrm{p}<0.05$ ) relative to $C x . p \mathrm{f}$ molestus, quinquefasciatus, or $p \mathrm{f}$ pipiens, respectively. Arrows denote direction of change relative to control. Parental populations are compared to one another and hybrid populations are compared to corresponding parentals.

population with the higher measured transmission rate or significantly higher than both parental populations (chisquared, $\mathrm{p}<0.05$; Table 1 ). Overall WNV transmission potential was evaluated by contrasting percent exposed transmitting among populations (\% infection $\%$ transmission; Figure 1). These results clearly depict the increased transmissibility of WNV-exposed hybrids, for which $C x$. quinquefasciatus transmission phenotype dominated in crosses with other species; and a synergistic effect on transmission is observed with crosses between bioformes of $C x$. pipiens (Figure 1). Anthropogenic and environmental changes are likely to continue to drive alterations to the extent and distribution of hybrids, which could lead to significant shifts in WNV competence among Culex populations.

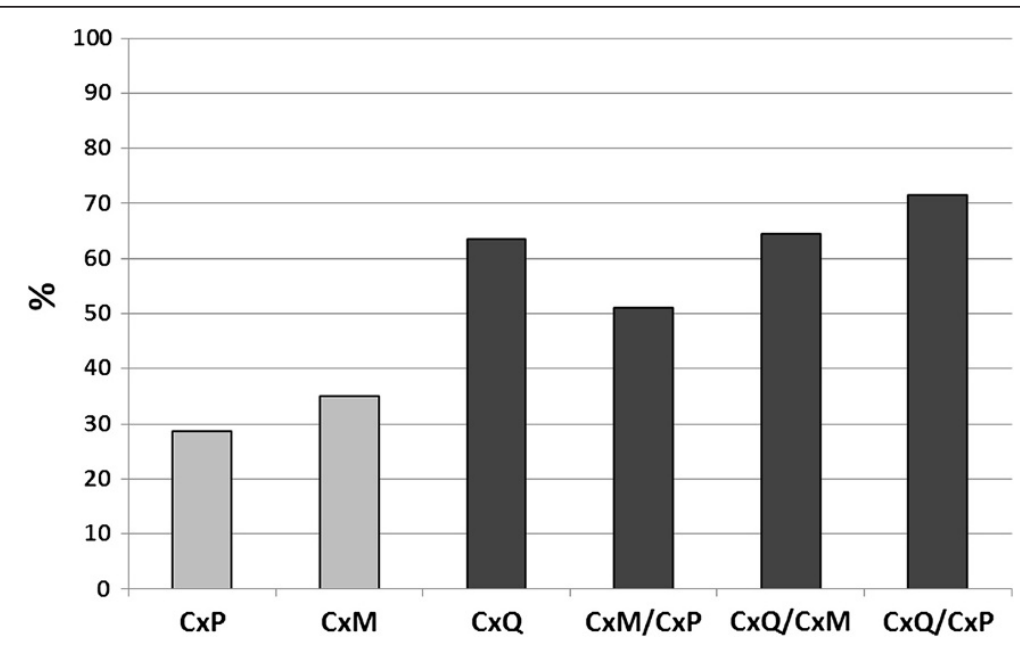

Figure 1 Percent of WNV-exposed Culex mosquitoes transmitting at day 13/14 post-feeding. CX.p f pipiens (CXP), CX.p f molestus (CXM), CX. quinquefasciatus $(C \times Q)$, as well as hybrid progeny of these lines were tested. Different shades represent statistically significant differences (chi-squared, $\mathrm{p}<0.05$ ). 
Variation in land use is significantly correlated to alterations in WNV, and urbanization not only increases environmental favorability for $C x$. pipiens, but also is likely to increase the potential for hybridization between bioforms $[19,20]$. In addition, recent reexamination of hybridization zones demonstates $C x$. quinquefasciatus genetic signature as far north as New York State [5]. A complete assessment of the vectorial capacity of individual hybrid populations, including evaluation of bloodfeeding behavior and survival, is required to fully characterize the effect on WNV transmission potential, yet these results suggest that the degree of hybridization among Culex pipiens complex mosquitoes is likely to be an important factor in WNV epidemiology.

\section{Competing interest}

The authors declare that they have no competing interests.

\section{Authors' contributions}

ATC directed experiments, analyzed data and wrote the manuscript. PAC carried out experiments and analyzed data. LDK directed and conceived the study. All authors read and approved the final manuscript.

\section{Acknowledgements \\ The authors would like to thank members of the Arbovirus laboratory insectary staff for assistance with this project. We thank the Wadsworth Center tissue and media facility for supplying cells and media for these studies. The construction of the Arbovirus laboratory insectary facilities was partially funded by National Institutes of Health (NIH) grant C06-RR-17715. This research was funded by NIH grant R01Al090159.}

Received: 23 April 2013 Accepted: 18 October 2013

Published: 23 October 2013

\section{References}

1. Farajollahi A, Fonseca DM, Kramer LD, Marm KA: "Bird biting" mosquitoes and human disease: a review of the role of Culex pipiens complex mosquitoes in epidemiology. Infect Genet Evol 2011, 11:1577-1585.

2. Andreadis TG: The contribution of Culex pipiens complex mosquitoes to transmission and persistence of West Nile virus in North America. J Am Mosa Control Assoc 2012, 28:137-151.

3. Kramer LD, Styer LM, Ebel GD: A global perspective on the epidemiology of West Nile virus. Annu Rev Entomol 2007, 53:61-81.

4. Kothera L, Zimmerman EM, Richards CM, Savage HM: Microsatellite characterization of subspecies and their hybrids in Culex pipiens complex (diptera: culicidae) mosquitoes along a north-south transect in the central United States. J Med Entomol 2009, 46:236-248.

5. Huang S, Molaei G, Andreadis TG: Reexamination of Culex pipiens hybridization zone in the Eastern United States by ribosomal DNA-based single nucleotide polymorphism markers. Am J Trop Med Hyg 2011, 85:434-441.

6. Eldridge BF: Diapause and related phenomena in Culex mosquitoes: their relation to arbovirus disease ecology. Curr Top Vector Res 1987, 4:1-28.

7. Harbach RE: Culex pipiens: species versus species complex taxonomic history and perspective. J Am Mosq Control Assoc 2012, 28:10-23.

8. Chevillon C, Eritja R, Pasteur N, Raymond M: Commensalism, adaptation and gene flow: mosquitoes of the Culex pipiens complex in different habitats. Genet Res 1995, 66:147-157.

9. Fonseca DM, Keyghobadi N, Malcolm CA, Mehmet C, Schaffner F, Mogi M, Fleischer RC, Wilkerson RC: Emerging vectors in the Culex pipiens complex. Science 2004, 303:1535-1538.

10. Turell MJ: Members of the Culex pipiens complex as vectors of viruses. J Am Mosa Control Assoc 2012, 28:123-126.

11. Kilpatrick AM, Meola MA, Moudy RM, Kramer LD: Temperature, viral genetics, and the transmission of West Nile virus by Culex pipiens mosquitoes. PLoS Pathog 2008, 4:e1000092.
12. Smith $J$, Fonseca DM: Rapid assays for identification of members of the Culex (Culex) Pipiens complex, their hybrids, and other sibling species (Dipteria: Culicidae). Am J Trop Med Hyg 2004, 70:339-345.

13. Bahnck CM, Fonseca DM: Rapid assay to identify the two genetic forms of Culex (Culex) pipiens L. (Diptera: Culicidae) and hybrid populations. Am J Trop Med Hyg 2006, 75:251-255.

14. Ebel GD, Rochlin I, Longacker J, Kramer LD: Culex restuans (Diptera:culicidae) relative abundance and vector competence for West Nile virus. J Med Entomol 2005, 42:838-843.

15. Komar N, Langevin S, Hinten S, Nemeth N, Edwards E, Hettler D, Davis B, Bowen R, Bunning M: Experimental infection of North American birds with the New York 1999 strain of West Nile virus. Emerg Infect Dis 2003, 9:311-322.

16. Sardelis MR, Turell MJ, Dohm DJ, O'Guinn ML: Vector competence of selected North American Culex and Coquillettidia mosquitoes for West Nile virus. Emerg Infect Dis 2001, 7:1018-1022.

17. Goddard LB, Roth AE, Reisen WK, Scott TW: Vector competence of California mosquitoes for West Nile virus. Emerg Infect Dis 2002, 8:1385-1391.

18. Kilpatrick AM, Fonseca DM, Ebel GD, Reddy MR, Kramer LD: Spatial and temporal variation in vector competence of Culex pipiens and Cx. restuans mosquitoes for West Nile virus. Am J Trop Med Hyg 2010, 83:607-613.

19. Brown HE, Childs JE, Diuk-Wasser MA, Fish D: Ecological factors associated with West Nile virus transmission, northeastern United States. Emerg Infect Dis 2008, 14:1539-1545.

20. Kent R, Harrington L, Norris D: Genetic differences between Culex pipiens f. molestus and Culex pipiens pipiens (Diptera: Culicidea) in New York. J Med Entomol 2007, 44:50-59.

doi:10.1186/1756-3305-6-305

Cite this article as: Ciota et al:: The effect of hybridization of Culex pipiens complex mosquitoes on transmission of West Nile virus. Parasites \& Vectors 2013 6:305.

\section{Submit your next manuscript to BioMed Central and take full advantage of:}

- Convenient online submission

- Thorough peer review

- No space constraints or color figure charges

- Immediate publication on acceptance

- Inclusion in PubMed, CAS, Scopus and Google Scholar

- Research which is freely available for redistribution

Submit your manuscript at www.biomedcentral.com/submit
C) BioMed Central 